\title{
A Case of Huge Substernal Goiter Causing Acute Respiratory Failure
}

\author{
Hyang Ae Shin, Sung Pyo Hong, In Kyung Sohn and Chul-Ho Kim \\ Department of Otolaryngology, Ajou University School of Medicine, Suwon, Korea
}

\author{
급성호흡부전를 유발한 거대 흉골하 갑상선종 1 예 \\ 신향애· 홍성표 · 손인경 · 김철호 \\ 아주대학교 의과대학 이비인후과학교실
}

\author{
Received February 17, 2009 \\ Accepted June 3, 2009 \\ Address for correspondence \\ Chul-Ho Kim, MD \\ Department of Otolaryngology, \\ Ajou University School of Medicine, \\ san 5 Woncheon-dong, Yeongtong-gu, \\ Suwon 443-721, Korea \\ Tel $+82-31-219-5269$ \\ Fax $+82-31-219-5264$ \\ E-mail ostium@ajou.ac.k
}

Substernal goiter is defined as a thyroid mass of which more than half is located below the thoracic inlet. As substernal goiter enlarges within the bony thoracic cavity, and vascular and visceral structures may slowly become compressed and compromised. Airway obstruction can occur due to the compression or the displacement of the trachea. Tracheal compression may rarely lead to severe respiratory compromise. Recently, we experienced a case of huge substernal goiter causing acute respiratory failure in a 63-year old female. We present this case with a review of the literature. Korean J Otorhinolaryngol-Head Neck Surg 2009;52:616-9

\section{서 론}

흉골하 갑상선종은 일반적으로 경부 갑상선 조직이 비대해 져 흉곽입구를 통하여 하방으로 성장하여 전체 부피의 $50 \%$ 이상이 흉곽 내에 위치하고 있는 갑상선 종괴를 지칭한다. ${ }^{1)}$ 대부분의 흉골하 갑상선종은 전종격동에 주로 발생하며, 10 $15 \%$ 정도에서 후종격동에 발생한다. ${ }^{2)}$ 서서히 자라고 초기 증상이 경미하여 수년 동안 무증상으로 지내는 경우가 많다. 여러 보고에서 다양한 빈도를 보이지만 많게는 $49 \%$ 의 환 자에서 발견 당시 무증상으로 보고되었다. ${ }^{1,3-5)}$ 일단 증상 이 나타나면 흉곽 내에 한정된 공간 내에서 갑상선종의 계 속적인 성장으로 주위 조직을 압박하는 것과 관련이 있다. 가장 흔한 증상은 기관 압박으로 인한 호흡장애 ${ }^{3,5)}$ 와 경부 종물 ${ }^{4}$ 이다. 드물게 급성호흡부전이 갑자기 발생할 수 있다. ${ }^{6)}$ 국내 문헌보고에선 경부 종물이 가장 흔한 증상으로 보고 되었고, ${ }^{7,8)}$ 급성호흡부전이 유발된 예는 보고된 바가 아직 없다.

최근 저자들은 급성호흡부전을 유발한 거대 흉골하 갑상
선종 1 예를 경험하였기에 문헌고찰과 함께 보고하는 바이다.

\section{증 례}

63세 여자 환자가 내원 1년 전부터 경미한 호흡곤란이 있 었고, 2 개월 전부터 서서히 심해져 응급실로 내원하였다. 과 거력상 20년 전부터 개인의원에서 갑상선 기능항진증으로 투약받아 왔고, 약 9 개월 전부터는 약 용량을 감량한 상태 였고, 30 년 전부터 류마티스 관절염으로 장기간 스테로이드 를 복용하였고, 거동이 불편하여 거의 침상에 누워지내는 상 태였다. 의식은 명료하였고, 연하곤란 및 흉통은 특별히 호 소하지 않았다. 이학적 검사상 심한 미만성 전경부 종대와 짧은 목 및 월상안 및 안구돌출, 체간은 비만한 상태였고, 사지는 가늘고 위축된 소견을 보였다. 후두내시경상 성대 움 직임은 정상이었다. 일반 혈액검사, 생화학검사 및 뇨검사에 서 특이사항은 없었고, 갑상선 기능검사상 유리 $\mathrm{T} 4, \mathrm{~T} 3$ 는 정상범위였고, $\mathrm{TSH} 0.01 \mathrm{uIU} / \mathrm{mL}$ (정상범위 0.25 5.00) 로 거의 정상 갑상선 기능 상태(euthyroid state)를 보였 
다. 내원 당시 시행한 동맥혈액가스분석검사상 $\mathrm{pH} 7.369$, $\mathrm{pCO}_{2} 49.6 \mathrm{mmHg}, \mathrm{pO}_{2} 76.3 \mathrm{mmHg}$, 산소포화도 $94.9 \%$ 소견을 보였다. 심전도검사에서 $\mathrm{RBBB}$, 동성빈맥, 심초음 파에서 좌심실기능부전(ejection fraction 40\%) 소견을 보 였고, 단순흉부촬영에서 심비대와 종격동 확장 소견을 보였 다(Fig. 1A). 경부 전산화단층촬영 및 흥부 컴퓨터단층촬 영상 일부 비균질하게 조영 증강되는 거대한 갑상선 종괴 가 양측 악하선 하연부터 흉곽입구를 통하여 대동맥궁을 지 나 기관 분기부까지 이르고 경계는 비교적 명확하였으며, 거 대 종괴로 인해 경부 주요 혈관이 양측 외곽으로 밀려있었 고, 흉곽내 기관이 전후방으로 협착된 소견과 양측 흉막삼 출 소견을 보였다(Fig. $1 \mathrm{~B}, \mathrm{C}$ and $\mathrm{D}$ ). 그 외 비정상적인 림 프절 증대는 보이지 않았다. 흉부외과와의 협진수술 계획하 에 거대한 종괴의 악성 가능성에 대한 세침흡인검사를 시행 하고 수술준비를 하던 중 입원 5일째 갑작스런 호흡곤란을 호소하였고 이내 급성호흡부전이 발생하였다. 기관내 삽관 을 시도하였으나 심한 미만성 전경부 종대와 짧은 목으로 인해 실패하였고, 후두기도마스크(laryngeal mask airway) 를 이용하여 기도를 확보한 후 수술실에서 전신마취하에 기관을 가리고 있는 갑상선 종괴를 최대한 하부로 견인한 후 첫 번째 기관륜에 기관절개술을 시행하였다. 경부 갑상선 종괴에서 시행한 세침흡인검사 결과 여포상 종양(follicular neoplasm)으로 보고되었다. 입원 7일째 흉부외과와 협진 하에 기존의 기관절개술의 수직 절개선을 흉부까지 연장한
후 갑상선 전절제술 및 정중 흉골절개술을 통한 흉골하 갑 상선종 절제술을 시행하였다. 수술시 반회후두신경의 손상 은 없었고, 상부부갑상선은 모두 보존되었고, 우측 하부부갑 상선은 확인이 안 되었고, 좌측 하부부갑상선은 흉쇄유돌근 에 이식하였다. 우측 갑상선 종괴의 하부가 흉곽입구를 통 하여 흉골하 갑상선 종괴와 연결되어 있었고, 대동맥궁 및 무명동맥과 기관사이에 위치하여 흉곽내 기관을 전후방으 로 압박하고 있었다(Fig. 2A, B and C). 종괴 제거 후 압박 되었던 기관은 다시 협착되는 소견은 보이지 않았고(Fig. $2 \mathrm{D})$, 기관절개술을 유지한 채로 수술을 종료하였다. 동결 절편검사 결과는 양성결절로 보고되었고, 수술로 제거된 갑 상선 종괴는 총 무게 $295 \mathrm{~g}$ 의 거대 갑상선종으로 우측, 좌 측, 흉골하 갑상선 종괴의 크기는 각각 $9 \times 4.5 \times 4 \mathrm{~cm}, 8 \times$ $4 \times 2.5 \mathrm{~cm}, 8 \times 6.5 \times 3.5 \mathrm{~cm}$ 였다 (Fig. $2 \mathrm{E}$ ). 최종병리조직 학적 검사상 선종성 증식(adenomatous hyperplasia)으로 보고되었다.

수술 후 환자는 술 전 진단된 좌심실부전, 폐부종 및 흉 막삼출증가로 45 일간 중환자실 치료를 받았고, 류마티스 관 절염으로 장기간 스테로이드 복용으로 인한 의인성 쿠싱증 후군으로 치료받았다. 술 후 합병증으로는 약 2 개월간의 일 과성 저칼슘혈증이 있었다. 환자는 $\mathrm{T}-\mathrm{Piece}$ 로 유지한 채 요양시설로 전원되었고, 이 후 10 개월간 외래 추적관찰하 면서 심폐기능의 회복 후 술 후 1 년에 성공적으로 발관하 였다.

Fig. 1. Chest $X$-ray shows severe mediastinal widening and cardiomegaly (A). Enhanced axial neck CT scan demonstrates a huge thyroid mass at the $2^{\text {nd }}$ level of tracheal ring, displacing internal jugular vein and common carotid artery laterally (B). Enhanced axial chest CT scan shows huge thyroid mass (asterisk) extending into the thoracic inlet and compressing the trachea (C), thyroid mass (asterisk) extending to the carina level (D) and bilateral pleural effusion.
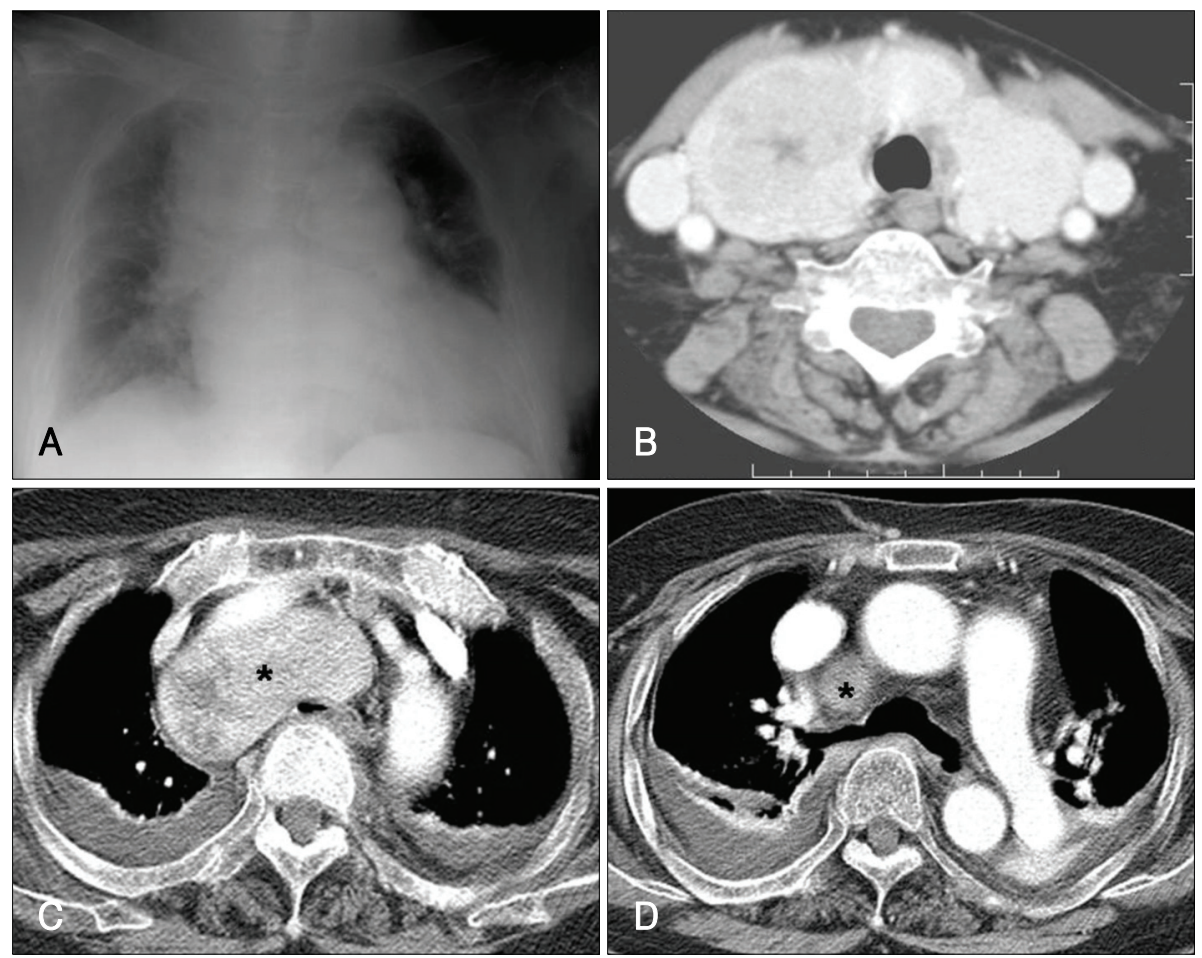

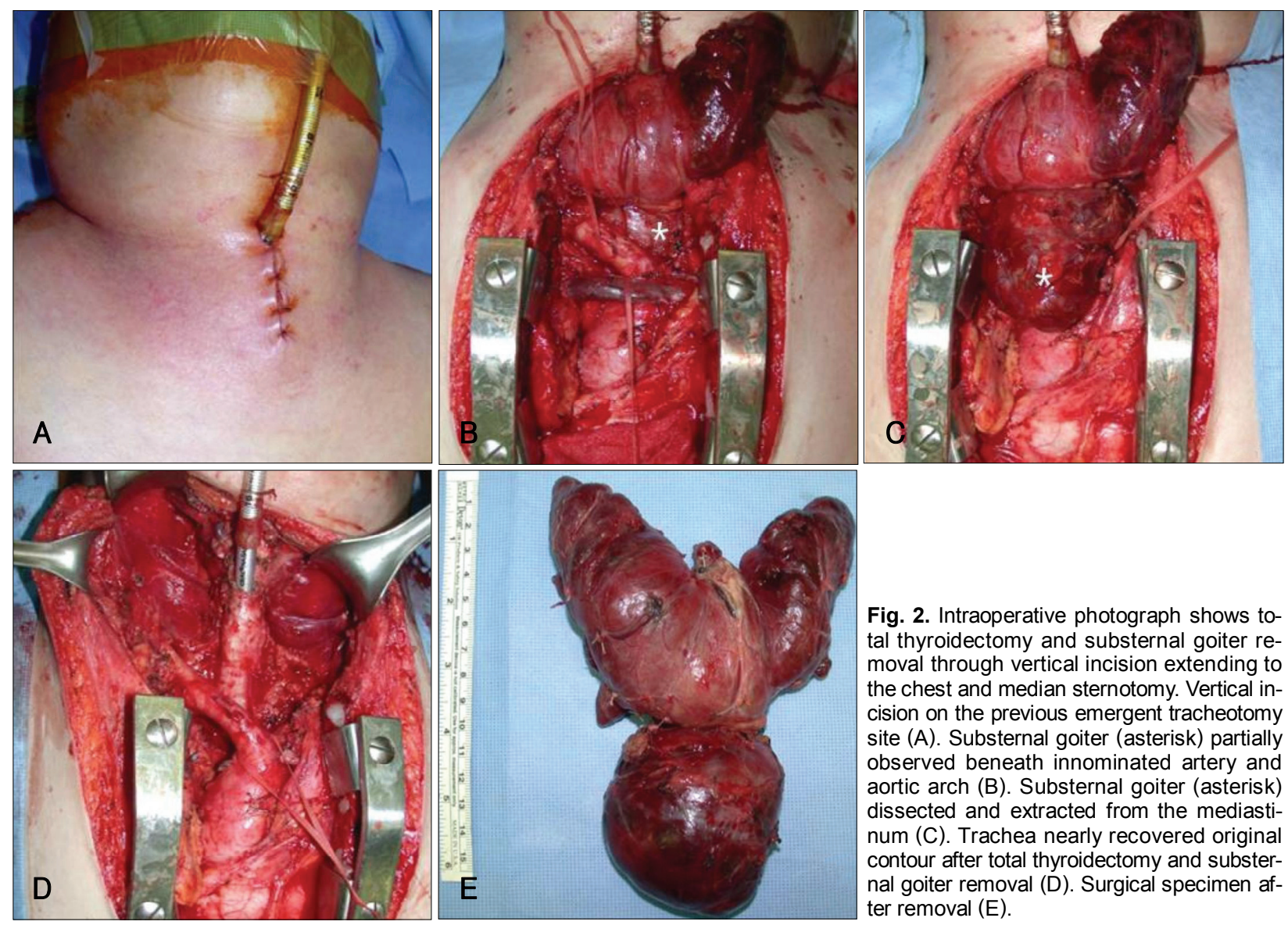

Fig. 2. Intraoperative photograph shows total thyroidectomy and substernal goiter removal through vertical incision extending to the chest and median sternotomy. Vertical incision on the previous emergent tracheotomy site (A). Substernal goiter (asterisk) partially observed beneath innominated artery and aortic arch (B). Substernal goiter (asterisk) dissected and extracted from the mediastinum (C). Trachea nearly recovered original contour after total thyroidectomy and substernal goiter removal (D). Surgical specimen after removal $(E)$.

고 찰

흉골하 갑상선종은 갑상선종의 $50 \%$ 이상이 흉곽입구 아 래에 위치하고 있는 것을 지칭하며, ${ }^{1)}$ 흉곽 내 동맥으로부터 혈액공급을 받고 이소성 갑상선 조직으로부터 유래되어 경 부 갑상선과의 연관성이 없는 원발성 흉골하 갑상선종과 경 부 갑상선의 하엽이 비대되어 흉곽 내로 들어가 발생하는 속발성 흉골하 갑상선종으로 나뉜다. ${ }^{29)}$ 대부분이 속발성 흥 골하 갑상선종으로 하갑상동맥의 분지로부터 혈액공급을 받는다. ${ }^{2)}$ 수년에 걸쳐 서서히 크기가 커지면서 흉곽입구를 통해 종격동 내로 들어가는데 이는 하방을 제외한 모든 방 향은 해부학적 구조상 제한이 있으며, 연하시 하방견인, 호 흡시 흉강 내 음압 및 중력 등의 요인에 의해 종격동으로 이 동하게 된다. ${ }^{10)}$ 최근에는 식이 요오드, 특히 요오드화 염의 섭취 증가로 거대 선종의 빈도가 줄고 있으나, 갑상선 절제 술을 시행 받은 환자들의 3 21\%로 다양하게 보고되고 있 다. 2,10-12) 주로 50대에서 발견되고, 남자보다 여자에서 발 생빈도가 높다. ${ }^{1}$ 조직병리학적 소견은 다결절성 갑상선종, 여포상 선종, 하시모토 갑상선염 등이 발생되고, ${ }^{1)}$ 그 외 악 성종양이 발생될 수 있고 그 빈도는 2 21\%로 경부갑상선
종의 악성종양 빈도와 유사하다. ${ }^{10,11)}$

흉골하 갑상선종의 가장 흔한 증상으로는 기관지나 식도 의 압박으로 인한 호흡곤란, 질식, 기침, 연하곤란 등이 있 으며, 그 외에도 진행성 애성, 흉막삼출, 일과성 허혈발작, 토혈, 성대마비, 횡격막 마비, Horner's syndrome, 상대정 맥 증후군 등도 발생할 수 있다. ${ }^{1,3,5,11,13,14)}$ 호흡기 감염에 의 해서 호흡곤란이 악화될 수 있고, 흉골하 갑상선종 내부에 외상성 혹은 자발성 출혈이 발생하여 갑상선종이 갑자기 커 지면서 갑작스런 기도폐쇄가 드물게 일어날 수 있다. ${ }^{6)}$ 본 환자에서 특별히 호흡기 감염을 의심할만한 소견은 보이지 않았고, 최종조직병리검사상 갑상선종 내부에 출혈 소견은 없었으나, 흉골하 갑상선종이 기관을 압박하고 있는 상태에 서 심폐기능 저하 등의 원인이 복합되어 급성호흡부전이 유 발된 것으로 추정된다. 거대 흉골하 갑상선종에서 갑작스런 급성호흡부전이 발생할 가능성을 충분히 인지하고 조직학 적 검사나 타과와의 협진 진행 등의 여러 가지 원인으로 수 술이 늦어질 경우 환자의 심폐기능을 고려하여 기도확보를 미리 계획하여야 본 증례에서 경험한 급성호흡부전을 예방 할 수 있겠다. 기관 삽관이나 기관절개술을 미리 시행하거 나, 종괴로 인해 기관 삽관이나 기관절개술이 어려울 때는 
후두기도마스크나 광봉, 굴곡성 기관지경 등을 이용한 기관 삽관도 고려할 수 있다.

흉골하 갑상선종의 진단시 흉부 단순방사선검사에서 종격 동 종괴, 기관편위, 기관압박 등을 관찰할 수 있으나 $30 \%$ 정도에서는 정상 소견을 보일 수 있다. ${ }^{11)}$ 전산화단층촬영 이나 자기공명촬영이 유용한 검사로 종괴의 위치 및 기관 지, 식도, 주요 혈관의 위치 등을 확인할 수 있어 수술접근 법을 결정하는데 특히 전산화단층촬영은 필수적인 검사이다.

세침흡인검사는 흥골하 갑상선종의 경우 접근이 용이치 않고, 출혈 등의 위험성 및 종종 채취된 검체의 부족으로 추천되지 않지만, ${ }^{10)}$ 경부 갑상선종에서는 조직병리학적 진 단을 위해 도움이 된다.

치료는 종괴의 악성 가능성, 주위구조의 압박증상으로 위 급한 상황이 일어날 수 있다는 점, 내과적 치료에 효과가 없 다는 점에서 수술이 최선의 치료방법이다. ${ }^{4,7)}$ 대부분은 경 부접근법을 통해 안전하게 종괴를 제거할 수 있으나 악성 이 의심될 경우, 후종격동에 위치한 경우, 대동맥궁 아래까 지 내려간 거대 종괴, 종격동 심부에 위치한 이소성 갑상선 종의 경우에는 흉골절개를 통한 접근법을 함께 시행하는 것 이 추천된다. ${ }^{5)}$ 본 환자는 악성 가능성도 배제할 수 없었고, 대동맥궁 아래까지 내려간 거대 종괴로 경부절개와 정중 흥 골절개술을 함께 시행하여 성공적으로 제거할 수 있었다.

술 후 발생할 수 있는 합병증으로는 성대마비, 부갑상선 기능 저하증, 출혈이 발생할 수 있으나 이는 일반 갑상선절 제술 후 발생하는 빈도와 같다. 단 일시적인 부갑상선 기능 저하증은 그 빈도가 더 높은 것으로 알려져 있다. ${ }^{12-14)}$ 그 외 종격동 감염, 기관 및 식도 천공이나 폐렴, 기흥 등이 있다. 흥골하 갑상선종은 양성 질환인 경우가 대부분이지만 흉 곽 내의 제한된 공간에 위치하므로 기도를 압박함으로써
급성호흡부전을 유발할 수 있는 질환이므로 술 전 기도확 보의 필요성에 대한 적절한 판단과 이에 대한 철저한 대비 가 요구된다.

\section{REFERENCES}

1) Katlic MR, Grillo HC, Wang CA. Substernal goiter. Analysis of 80 patients from Massachusetts General Hospital. Am J Surg 1985;149(2): 283-7.

2) Mack E. Management of patients with substernal goiters. Surg Clin North Am 1995;75 (3):377-94.

3) Agha A, Glockzin G, Ghali N, Iesalnieks I, Schlitt HJ. Surgical treatment of substernal goiter: an analysis of 59 patients. Surg Today 2008; $38(6): 505-11$.

4) Erbil Y, Bozbora A, Barbaros U, Ozarmağan S, Azezli A, Molvalilar S. Surgical management of substernal goiters: clinical experience of 170 cases. Surg Today 2004;34 (9):732-6.

5) Cohen JP. Substernal goiters and sternotomy. Laryngoscope 2009; (4) :683-8.

6) Youk EG, Oh SK, Choe KJ, Youn YK, Noh DY, Kim JH. Surgical treatment of substernal goiters. J Korean Surg Soc 1997;53 (6):795-801.

7) Choi JO, Kim YH, Lee JY, Kim YH, Sung TH, Yoo HK. Surgical management of substernal goiter. Korean J Otolaryngol-Head Neck Surg 1998;41 (7):935-9.

8) Falor WH, Kelly TR, Jackson JB. Intrathoracic goiter. Surg Gynecol Obstet 1963;117:604-10.

9) Singh B, Lucente FE, Shaha AR. Substernal goiter: a clinical review. Am J Otolaryngol 1994;15 (6) :409-16.

10) Wright CD, Mathisen DJ. Mediastinal tumors: diagnosis and treatment. World J Surg 2001;25 (2) :204-9.

11) Torre G, Borgonovo G, Amato A, Arezzo A, Ansaldo G, De Negri A, et al. Surgical management of substernal goiter: analysis of $237 \mathrm{pa}-$ tients. Am Surg 1995;61 (9) :826-31.

12) Arici C, Dertsiz L, Altunbas H, Demircan A, Emek K. Operative management of substernal goiter: analysis of 52 patients. Int Surg 2001;86 (4):220-4.

13) Ozdemir A, Hasbahceci M, Hamaloglu E, Ozenc A. Surgical treatment of substernal goiter. Int Surg 2000;85 (3):194-7.

14) Mellière D, Saada F, Etienne G, Becquemin JP, Bonnet F. Goiter with severe respiratory compromise: evaluation and treatment. Surgery 1988;103 (3) :367-73 